\title{
LOS PARADIGMAS DEL DERECHO Y LOS MODELOS \\ DE LA FÍSICA
}

\author{
The Paradigms of LaW and \\ PHYSICS MODELS
}

\author{
Os PARADIgMAS DO DIREITO E OS \\ MODELOS DA FÍSICA
}

CARLOS JESÚS MOLINA-RICAURTE*

* Universidad Santo Tomás, Colombia. carlosjesus80@gmail.com

RECIBIDO: 29 DE AGOSTO DE 2015. ENVío A PARES: 2 DE SEPTIEMBRE DE 2015. APRoBAdo PoR PARES: 12 DE NOVIEMBRE DE 2015. ACEPTAdo: 18 DE NOVIEMBRE 2015.

DOI: $10.5294 / D I K A .2016 .25 .1 .4$ 


\section{RESUMEN}

Los cambios por los que atraviesa el Derecho en la actualidad se deben no solo a transformaciones sociales, económicas y politicas experimentadas recientemente, sino también a las condiciones propias de la disciplina. Para la mayoría de estudiosos han pasado desapercibidos elementos que hoy denotan mayor importancia. Para retomar estos elementos no es necesario escribir una nueva historia del Derecho, basta adoptar un enfoque naturalista integrando los elementos hasta ahora ignorados a fin de lograr una mirada de conjunto. En el mundo natural, los gases exhiben características tales como la fluidez e invisibilidad; un nuevo enfoque del Derecho debe considerar estas mismas características. En razón de los problemas que enfrenta y de nuevos paradigmas epistemológicos, para abordar el mismo conviene hablar de un Derecho gaseoso, como aquel capaz de entender estas dinámicas, frente a formas tales como el Derecho sólido y el Derecho líquido. Nuevo Derecho a nuevas circunstancias. Ahora bien, para entender ese nuevo Derecho deben renovarse las formas de enseñanza de sus juristas e intérpretes, sobre todo, los enfoques epistemológicos para abordar la materia.

\section{PALABRAS CLAVE}

Derecho; enseñanza del Derecho; epistemologia; historia del Derecho; naturaleza. 


\section{ABSTRACT}

The Law is currently going through some changes, due not only to the recent social, economic and political transformations, but also to the very conditions of Law. Certain elements that are now important have gone unnoticed by most scholars and, in order to address them, it is not necessary to write a new history of Law; it is enough to adopt a naturalistic approach that incorporates these previously ignored elements in order to achieve an overall picture. In the natural world, gas is fluid and invisible, which are characteristics that a new approach of Law should also exhibit. In light of the problems now faced by Law and the new epistemological paradigms, we should speak of a 'gaseous law', as one capable of understanding such dynamics, compared to solid Law and liquid Law. A new Law for new circumstances. Now then, understanding this new Law requires the renewal of the forms in which lawyers and interpreters of the law are educated, particularly the epistemological approaches to address the matter.

\section{KEYWORDS}

Law; Teaching Law; Epistemology; History of Law; Nature. 


\section{RESUMO}

As mudanças pelas que o Direito está atravessando atualmente se devem não somente a transformações sociais, econômicas e políticas recentes, mas também às condições próprias do Direito. Para a maioria de estudiosos, os elementos que hoje denotam mais importância têm passado desapercebidos. Para retomar estes elementos não é necessário escrever uma nova história do Direito, basta adotar um enfoque naturalista integrando os elementos ignorados até agora a fim de alcançar uma visão de conjunto. No mundo natural, os gases exibem características tais como a fluidez e invisibilidade; um novo enfoque do Direito deve considerar estas mesmas características. Devido aos problemas enfrentados pelo Direito e de novos paradigmas epistemológicos, para abordar o mesmo convém falar de um Direito gasoso, como aquele capaz de entender estas dinâmicas, diante a formas tais como o Direito sólido e o Direito líquido. Novo Direito a novas circunstâncias. Agora bem, para entender esse novo Direito devem renovar-se as formas de ensino dos juristas e intérpretes do Direito, principalmente, os enfoques epistemológicos para abordar a matéria.

\section{PALAVRAS-CHAVE}

Direito; ensino do Direito; epistemologia; história do Direito; natureza. 
Sumario: Introducción; 1. Derecho sólido; 2. Derecho líquido; 3. Derecho gaseoso; 4. El Derecho y las ciencias de la naturaleza; Conclusiones; Bibliografía.

\section{INTRODUCCIÓN}

La certeza, la seguridad y la estabilidad, otrora deificadas por los glosadores, parecen diluirse con el tiempo. A cambio, el Derecho parece sumirse en la incertidumbre, la inseguridad y la inestabilidad. La tendencia del mundo contemporáneo marca una marcha del Derecho al estado de naturaleza, pero más que regresión o involución, estos cambios sugieren un nuevo estado en su evolución.

Para entender estos fenómenos o cambios vamos a concebir las categorías de derecho sólido, derecho líquido y derecho gaseoso, que permiten no solo conceptualizar la disciplina, sino también situarla en un contexto, reconociendo su trayectoria histórica. Cierto es que estas categorías no son nuevas en el debate jurídico. Ya el notario y escritor español Rodrigo Tena alude a las categorías de derecho sólido y derecho líquido en una disertación presentada el 12 de marzo de 2009, ante el Colegio Notarial de Madrid, ${ }^{1}$ seguida de una publicación en el diario El Mundo, de España, del 30 de septiembre de 2009, titulada "Derecho líquido y abuso de poder". 2 Casi sin variación fue acogida la categoría de derecho líquido por Fernando Luis Ruiz Piñeiro, magistrado del País Vasco, en una publicación en la revista Nómadas, titulada "Sociedad subsiguiente a la Modernidad, seguridad jurídica diluida y jueces en proceso de licuefacción". ${ }^{3}$ Tena advierte claramente que la categoría de derecho líquido se basa en el concepto de "modernidad líquida", definido por el sociólogo polaco Zigmunt Bauman; ${ }^{4}$ en lo que se refiere a la categoria de derecho sólido (el derecho científico, técnico, que justamente sirve de freno al abuso del poder y es el principal garante de la libertad), parece que llegara por inferencia, como el opuesto al derecho líquido (un derecho amorfo, adaptable, que no sirve de freno ni garantía de nada). Sin demeritar la poderosa intuición del notario Tena, de paso acogida por el magistrado Ruiz Piñeiro, encuentra ciertas limitaciones a la hora de justificar las categorías de derecho sólido y derecho líquido, pues ambos parecen moverse, más bien, a un nivel metafórico, por lo que las categorias, al menos la de derecho sólido, resulta privada de una entidad propia, quedándose en un grado muy elevado de abstracción.

Por su parte, el profesor Javier Pamparacuatro, en su artículo "En torno a la crisis del Derecho", hace un análisis concienzudo acerca de la categoria de derecho

1 Cfr. Rodrigo Tena, "Derecho líquido. Reflexiones en torno a la Ley 41/2007 de Reforma Hipotecaria”, en El Notario del siglo XXI (25) (2009), en http://www.elnotario.es/index.php/academiamatritense-del-notariado/1604-derecho-liquido-reflexiones-en-torno-a-la-ley-41-2007-de-reforma-hipotecaria-0-2764456144314684, fecha de consulta: 8 de abril de 2016.

2 Cfr. Rodrigo Tena, "Derecho líquido y abuso de poder", El Mundo (2009), en http://www.elmundo. es/opinion/tribuna-libre/2009/09/19536117.html, fecha de consulta: 8 de abril de 2016.

3 Cfr. Fernando Luis RuIz PIÑEIRo, "Sociedad subsiguiente a la Modernidad, seguridad jurídica diluida y jueces en proceso de licuefacción”, en Nómadas (26) (2010), p. 10, en http://www.redalyc.org/ articulo.oa?id=18118916001, fecha de consulta: 8 de abril de 2016.

4 Cfr. Zigmunt Bauman, Modernidad liquida, Buenos Aires, Fondo de Cultura Económica, 2002, pp. 7-20. 
gaseoso, el cual caracteriza como un derecho espectral, fantasmal, evanescente. ${ }^{5}$ Haciendo un parangón, Pamparacuatro dispone de más recursos argumentativos que Tena y Ruiz Piñeiro, y es más cuidadoso en el uso de imágenes en el discurso, lo que hace de su propuesta aún más robusta y sólida; no obstante, el carácter eminentemente legalista que confiere al Derecho, lleva a identificarlo inevitablemente con la ley, si no a simplificarlo ${ }^{6}$ y excluir otras fuentes del objeto del Derecho, so pretexto de mayor cientificidad, aludiendo a una supuesta "dispersión de las fuentes"7 como manifestación de la crisis. De esta manera, Pamparacuatro desconoce avances en materia de teoría, historia y sociologia del Derecho, que aceptan la pluralidad de sus fuentes, lo que le resta validez a su propuesta. Si se dijo que Tena acusaba un grado alto de abstracción, tal vez deba decirse que Pamparacuatro cae en un nivel elevado de idealización del Derecho. Para probar esta última afirmación basta con constatar el uso recurrente que hace de la palabra "ideal", no más como adjetivo que como sustantivo. ${ }^{8}$

La presente propuesta, más que a la pregunta por el fundamento del Derecho, se orienta a la pregunta sobre el ser del Derecho, esto es, su estatuto ontológico, sus condiciones y posibilidades como objeto del conocimiento. Por un lado, resiste la mirada metafórica del Derecho, evitando con esto caer en su abstracción y, por otro, conjura la fuerte idealización del mismo, de la que no han podido escapar muchos de sus estudiosos. La reflexión que se desarrolla a continuación no parte del análisis en el vacío, por el contrario, aboga por un estudio contextualizado del Derecho, como producto de la cultura y objeto de evolución constante; en esa medida, indaga a través de la historia del Derecho. En cuanto al uso de un modelo de la física, lo justifica el hecho de aproximarse a la realidad, toda vez que guarda un grado de similitud con los sistemas reales. "Una de las virtualidades de los modelos es que se pueden describir con la ayuda de esquemas, diagramas e, incluso, en ocasiones, con la ayuda de un análogo material. De este modo, nos permiten acercarnos a sistemas inaccesibles para nuestros sentidos". ${ }^{10}$

Esta lectura de la historia del Derecho no es para nada nueva, pero sí procura ser más atenta a aspectos ignorados hasta entonces, dándoles un lugar en la exposición. Consiste en un abordaje a la historia del Derecho, al interior del Derecho mismo, concibiéndola como una historia natural. El uso que hace de la terminologia no es, de ningún modo, arbitrario, pues, aunque se tome prestada de otra disciplina tan distinta como la física, resulta útil por las posibilidades que brinda para la definición de elementos conceptuales clave, permitiendo mostrar un desarrollo más articulado y menos accidentado del Derecho. Se pone de presente,

Cfr. Javier Pamparacuatro, "En torno a la crisis del Derecho", en Revista de Derecho Político (92) (2015), p. 192, en http://revistas.uned.es/index.php/derechopolitico/article/view/14424/12882, fecha de consulta: 8 de abril de 2016.

6 Ibid., pp. 170-171.

$7 \quad$ Ibid., pp. 185-186.

$8 \quad$ Ibid., pp. 170, 176, 177, 191, 192.

9 Cfr. Joan Josep Solaz-PortolÉs, "Sobre cómo el conocimiento científico intenta aproximarse a la realidad”, en Revista Brasileira de Ensino de Física 34 (3) (2012), p. 1308-2, en http://www.scielo. br/pdf/rbef/v34n1/v34nla08.pdf, fecha de consulta: 8 de abril de 2016 . Ibid., p. 1308-3. 
entonces, un modelo epistemológico basado en una nueva forma de entender los fenómenos jurídicos a partir de las ciencias de la naturaleza. Este nuevo modelo explicativo logra establecer la naturaleza del Derecho, ya no a partir de una explicación finalista, que busca en todo tiempo una causa primera de la realidad, sino desde la causalidad, que busca el nexo de los fenómenos con la causa inmediata, esto es, la realidad. Si hay posibilidad de establecer una ontología del Derecho es a partir de las concreciones que este ha tenido a través de la historia, pero apreciando las múltiples concreciones en conjunto. Por supuesto que deben distinguirse unas concreciones de otras para poder realizar un estudio, con esto tampoco estamos diciendo que estas deban verse de manera aislada, llevando a absolutizar una concreción sobre las otras; más bien, deben tomarse como una manera en que se muestra el Derecho en algún momento de su evolución, donde ninguna resulta ajena a la otra sino que determina la aparición de la otra; tampoco puede decirse que la nueva concreción niegue totalmente la anterior, por el contrario, la contiene y permanece unida a un todo. Así, el método más conveniente y apropiado para este tipo de investigación es el dialéctico.

"Los paradigmas científicos son modelos, esquemas, patrones que estructuran la manera en que los científicos hacen ciencia, de manera tal que guían su actividad, declaran qué problemas pueden investigar y los posicionan en tradiciones académicas". ${ }^{11}$ Aunque el artículo parece sugerir la ruptura entre un paradigma y otro, al contrario, hace el esfuerzo por distanciarse de esa tendencia, entendiendo que "la adscripción del científico a un solo paradigma puede resultar un tanto empobrecedora". ${ }^{12}$ A eso hay que agregar que: "En el campo de la epistemología y el Derecho, contar con distintos lugares desde los cuales pueda observarse y comprenderse el fenómeno es crucial a fin de captarlo adecuadamente, comprenderlo y abarcarlo en su totalidad". ${ }^{13}$

Los paradigmas científicos tienen origen en una situación histórica concreta, ofreciendo un horizonte de sentido que, de momento, puede responder de manera satisfactoria a ciertas cuestiones que se plantea el Derecho, pero con el tiempo se hacen insuficientes para comprender y dar respuesta a las nuevas situaciones que desafian al Derecho. Mal se haría, pues, en otorgar un valor objetivo, inmutable y atemporal a algún paradigma en especial, más sabiendo que todos son fruto del esfuerzo de la razón humana por aproximarse a la realidad, en vez de eso, parece, más bien, que concurren entre estos.

La idea de que la única esencia del Derecho nos la proporcione una única Teoría o Filosofia del Derecho no es realista. Por más sólida, bien definida y espléndida que

11 Elvio Galati, "Visión compleja de los paradigmas científicos y la interpersonalidad en la ciencia", en Cinta moebio (44) (2012), pp. 124-125, en http://www.scielo.cl/pdf/cmoebio/n44/art03.pdf, fecha de consulta: 8 de abril de 2016.

12 Leonarda GaRCía JimÉnEZ, "Aproximación epistemológica al concepto de ciencia: Una propuesta básica a partir de Kuhn, Popper, Lakatos y Feyerabend”, en Andamios 4 (8) (2008), p. 193, en http://www.scielo.org.mx/scielo.php?script=sci_arttext\&pid=S1870-00632008000100008, fecha de consulta: 8 de abril de 2016.

13 Elvio GalATI, "Visión compleja de los paradigmas científicos y la interpersonalidad en la ciencia", op. cit. (2012), p. 133. 
nos pudiera parecer alguna versión especial de la Teoría del Derecho, la misma no será capaz de evitar que el talento humano en el futuro pueda aportar esquemas más completos y adecuados para dar respuesta a los problemas que vayan adquiriendo relevancia para la reflexión y práctica jurídicas. No sería científico que hoy renunciemos a perder la libertad para analizar al Derecho desde nuevas perspectivas. ${ }^{14}$

El estudio de la naturaleza del Derecho, planteamiento central de esta disertación, más que una idea exótica, pretende demostrar que la naturaleza es inherente al despliegue del Derecho (desde los puntos de vista conceptual y fáctico) como hecho peculiar y manifiesto de la naturaleza del Derecho. La etimología de la palabra física nos da la primera pista. Physis o Фuбıs (en griego) significa naturaleza. Fue Aristóteles el primero en elaborar una concepción acabada acerca de physis (naturaleza), como aquello que tiene en sí movimiento. ${ }^{15}$ Lo que tiene en sí movimiento tiene un origen y pasa también por un desarrollo. Hablar de una física del Derecho denota que el Derecho mismo es dinámico y cambiante, lo que permite hablar de una naturaleza del mismo, la cual se muestra en varios estados, puede hablarse de un estado sólido, un estado líquido y, por último, un estado gaseoso del Derecho. No se relacionan precisamente con etapas históricas, aunque, en principio, parece que lo estuvieran; más bien se relacionan con el concepto de Derecho. El Derecho deviene naturaleza, esto es, movimiento, toda vez que contiene el movimiento en sí. No basta aludir a la física del Derecho como una etapa más o la transición de una etapa a otra, sino como la única forma posible en que se concreta y se concibe realmente el Derecho. No es el tiempo actual el que nos obliga a hablar de un estudio natural del Derecho, sino que es la naturaleza la que nos permite hablar de Derecho hoy.

\section{DERECHO SÓLIDO}

En este primer pasaje intentará explicarse la tesis llamada del derecho sólido, que concibe el Derecho a partir de un fundamento sustancial o material, y lo sitúa en la Antigüedad aunque, como se verá a continuación, influyó en la mayor parte de la historia de Occidente. Se comenzará por la filosofía como fuente primaria para conocer la forma como los antiguos concibieron el mundo y su ordenación, y la influencia del Derecho en la constitución de las bases del pensamiento occidental; por último, la separación entre filosofia y Derecho, después de estar intimamente relacionados desde sus inicios.

Así como es correcto decir que "la mayoría de los primeros filósofos" ${ }^{16}$ se interesaron por temas de la naturaleza, no es menos que la noción más básica del Dere-

14 Víctor Manuel RoJAs Amand, "Cuatro paradigmas de la epistemología jurídica”, en Jurídica: Anuario del Departamento de Derecho de la Universidad Iberoamericana (36) (2006), p. 420, en http://www. juridicas.unam.mx/publica/librev/rev/jurid/cont/36/pr/pr23.pdf, fecha de consulta: 8 de abril de 2016.

82

15 “...la naturaleza es un principio de movimiento y cambio", de tal modo, "las cosas tienen una naturaleza si poseen ese principio”. ARIstóteles, Fisica, Madrid, Gredos, 1998, III 1, 200 b 12.

16 Rodolfo Mondolfo, El pensamiento antiguo, vol. 1, Buenos Aires, Losada, 1942, p. 37. 
cho conocida proviene de la visión del cosmos que tenían los griegos. Los griegos suponían un orden en el cosmos y el fundamento de ese orden lo situaban en la mesura y la justicia.

La concepción de uniones entre los elementos de la naturaleza da, de la misma manera, una idea de enemistades que se traban entre los elementos. Esa especie de fuerza que restablece las cosas a su propio estado puede considerarse como justicia. ${ }^{17} \mathrm{El}$ concepto de Derecho está intimamente unido a la idea de naturaleza, fueron los sofistas quienes deslindaron uno del otro, al contraponer cultura y naturaleza. El ideal de los sofistas concebía al hombre libre del imperio de la naturaleza y de su yugo, a cambio de esto, el hombre debía enseñorearse y someter la naturaleza - aquí se encuentra una de las expresiones más acabadas del pensamiento humanista antiguo-. Por último, la polis, forma o representación del orden civil, terminó por concebirse en oposición al estado de naturaleza.

Ciertamente, entre ley y polis existe una relación sustancial. Como advirtiera Heráclito a sus conciudadanos durante el sitio de Atenas, no menos importante que la protección de las murallas es la preservación de la ley y el orden que estos garantizan. La ley constituye, pues, la muralla espiritual de la polis. ${ }^{18}$ Así como los muros sirven para mantener a salvo la ciudad de los enemigos, la ley sostiene la virtud de los ciudadanos.

Inicialmente la ley se identificaba con un factor sustancial, como era la tierra (nomos). ${ }^{19}$ Más adelante, en los poemas homéricos, encontramos la ley como condición necesaria de una vida civilizada ${ }^{20}$ pero sin un vínculo con la tierra (nomos). Según esta breve descripción, la ley había pasado de una identificación con la tierra (nomos) a la relación directa con la forma de vida ciudadana.

El respeto por la ley es sintoma de la buena salud de la ciudad, ${ }^{21}$ del mismo modo, de la buena disposición de todos y cada uno de los habitantes de la polis. El buen ciudadano se define a partir de la sujeción y el cumplimiento de la ley. En ese sentido, la implicación moral de la ley pone las bases del ordenamiento político griego, así como las bases del pensamiento de Occidente.

17 Cfr. Manuel Oswaldo Ávila VÁsguez, "En torno a la sentencia de Anaximandro. Dos interpretaciones sobre la justicia”, en Universitas Philosophica (56) (2011), pp. 61-83, en: http://revistas.javeriana.edu.co/index.php/vniphilosophica/article/view/11030/9041, fecha de consulta: 8 de abril de 2016.

18 Cfr. Werner JAeger, Alabanza de la ley. Los origenes de la filosofia del derecho y los griegos, Madrid, Instituto de Estudios Políticos, 1953, p. 43.

19 “... el sustantivo nomós, en su primera acepción, significa 'lugar repartido, dividido en parcelas', 'campo de pastoreo'. Y nómos — solo modificando el acento- designa una 'regla', 'uso', 'costumbre”. Javier BARBIERI, "Physis frente a nomos: El eterno retorno”, en Díkaion 20 (1) (2011), pp. 7475, en http://www.scielo.org.co/pdf/dika/v20n1/v20n1a04.pdf, fecha de consulta: 8 de abril de 2016.

20 "En el pensamiento homérico, pues, era dike la línea de demarcación entre la barbarie y la civilización". Werner JAEGER, Alabanza de la ley. Los orígenes de la filosofia del derecho y los griegos, Madrid, Instituto de Estudios Políticos, 1953, p. 20.

21 Ibid., pp. 38-41. 
La ley se refiere, en primer lugar, a la ordenación interna del individuo, no obstante, sirve también para estructurar un orden en la realidad. Pensadores como Parménides, Sócrates y Platón concibieron la ley como la estructura fundamental de la realidad. Para Sócrates, por ejemplo, la ordenación interna de los individuos era garantía de una buena ordenación de la sociedad. Esta ordenación interna se basaba en las relaciones entre las partes del alma; la parte superior estaba referida a la razón; las que le seguian eran la parte sensitiva y la anímica; las tres se relacionaban entre sí, aunque propiamente las dos últimas debían someterse a la parte superior; estas no eran necesariamente tiranizadas por aquella, sino que eran convenientemente conducidas. Algunas veces, la parte superior se identificaba con el timonel de una nave; en otras, en cambio, con un cochero. La realidad se configuraba a partir de la relación entre el mundo de las ideas y del mundo sensible; esta relación, al parecer, era más estrecha que en la tripartita alma humana. Partiendo de que las ideas no se reducían a solo tipos o modelos mentales situados fuera de la realidad, sino que el mundo de lo sensible participaba, más o menos, del mundo de las ideas, pasando de imagen a sombra (phantasmata) de la realidad, en esa medida, los objetos eran más reales en cuanto participaran de las ideas. Lo ideal no es algo distinto de lo real.

La ley es eterna, constitutiva y racional. Es eterna y, en esa medida, es divina. Tiene, además, una función ordenadora del universo, ${ }^{22}$ de ahí que se convierta en fundamento de la realidad. A la función ordenadora de la realidad se suma la función ordenadora del alma humana, de la cual proviene su carácter racional. Esta ley eterna, constitutiva de la realidad y racional, tiene su manifestación más perfecta en la polis. La ley, a su vez, tiene una función política, por eso deviene en razón de Estado.

Sin embargo, la historia de Occidente demuestra que no siempre la forma politica predominante fue la estatal. Aparte de la hegemonía, primero griega y, luego, romana, se encuentran otras formas de organización política y, por tanto, la coexistencia de varios tipos de Derecho, entre otros, el germánico. A pesar de que el Derecho dominante fuera el de la potencia conquistadora, en muchos aspectos, sobre todo en la vida cotidiana, siguió operando el Derecho de los vencidos. Se observa, entonces, cómo junto al Derecho romano seguía aplicándose el Derecho germánico. Lo más llamativo es el modo como ambos labraron la historia jurídica de Occidente. El filósofo francés Michel Foucault ${ }^{23}$ hace un análisis concienzudo al respecto.

Con el objeto de hacer una disertación sobre la verdad y las formas juridicas, Foucault analizó las formas de procedimiento predominantes en Occidente, empezando por el procedimiento judicial de la prueba, a este se refirió como un sistema basado en la intervención de dos partes, una parte que trababa el proceso judicial contra la otra. Este tipo de procedimiento no se preocupaba tanto por llegar a la verdad.

22 Los griegos consideraban que antes de constituirse el mundo reinaba el caos. Por tanto, el mundo es resultado de una separación del caos y de una labor de ordenación.

23 Cfr. Michel Foucault, La verdad y las formas jurídicas, Barcelona, Gedisa, 1992. 
La otra forma de procedimiento se basaba en el testimonio, para la cual la verdad ocupaba el lugar central, independientemente de la situación de las partes en el proceso. Ambas formas jurídicas se situaron en Grecia. En los poemas homéricos y en las tragedias griegas se encuentran ejemplos de los dos.

No obstante, las dos formas de procedimiento judicial siguieron evolucionando, manifestándose de muy distintas maneras a lo largo de la historia jurídica de Occidente. El procedimiento judicial de la prueba, mucho más arcaico, estaba de cierta forma emparentado con el procedimiento judicial del Derecho germánico, el cual se caracterizaba por ser una continuación de la guerra, tomando forma de procedimiento solamente para garantizar que se cumplieran las reglas y que el conflicto no se extendiera indiscriminadamente al resto de la comunidad. Las únicas partes que intervenían en el proceso eran el ofendido y el ofensor; podía hacerlo un tercero, pero solo en calidad de garante. El denunciante debía estar preparado para irse a duelo con el denunciado, por tanto, el procedimiento se convertía en una medición de fuerzas. Luego, este procedimiento se fue depurando de su forma bárbara, y ya no precisaba del enfrentamiento directo entre las dos partes, sino que dejaba solamente al denunciado en el proceso, quien debía probar su fuerza de muy distintas maneras. ${ }^{24}$ Esta variante del Derecho germánico se conoció como Derecho feudal.

La otra forma de procedimiento judicial era la del testimonio, asociada a una intensa organización estatal, por eso tuvo tanto éxito en Roma y llegó a un nivel muy alto de desarrollo en el Derecho romano. La historia jurídica de Occidente muestra una oscilación. Así, cada vez que emergia en Occidente una estructura estatal fuerte, sobrevenía el Derecho romano. A partir del siglo V, con la caída del Imperio romano de Occidente, se vio un fuerte influjo del Derecho de los pueblos bárbaros, principalmente el de los germanos. Con la instauración del Imperio carolingio, hacia el siglo VIII, se suscitó de nuevo el interés por el Derecho romano y sus instituciones, de ahí que el intento de su restablecimiento durara hasta el siglo IX, en que tuvo lugar la caída del Imperio carolingio. En adelante, el llamado Derecho de Estado o Derecho romano fue eclipsado por el Derecho feudal, variante del germánico, que resultaba más adecuado a los pequeños reinos europeos. Este periodo se caracterizó por la inestabilidad politica. La guerra era una constante entre los distintos reinos. La economía no se basaba en el intercambio con otros pueblos. La circulación de bienes se daba a través del asalto, el pillaje y el pago de rescates. La guerra no se consideraba contraria al Derecho, antes bien, el Derecho servía para reglar los conflictos entre particulares. El Derecho germánico tenía su fuente inmediata en la costumbre, por tanto, no precisaba de la ley, menos aún, de una unidad política centralizada. Esta autonomía social frente al poder y control político fue propia de la Edad Media. Nos encontramos así con una variante nueva del Derecho germánico, el Derecho medieval. ${ }^{25}$

24 Había de distintos tipos, las pruebas sociales, las pruebas de tipo verbal, por último, las pruebas fisicas u ordalias. Cfr. Michel Foucault, La verdad y las formas jurídicas, op. cit.

25 Cfr. Paolo Grossi, Mitología jurídica de la modernidad, Madrid, Trotta, 2003. 
Con la formación de las ciudades y la intensificación del comercio sobrevinieron periodos más extensos de paz y concordia. La actividad social se intensificó, esto llevó a que la costumbre se convirtiera en principal fuente del Derecho medieval. Fueron la costumbre, adoptada por las agremiaciones de comerciantes, y la tradición, las que permitieron dirimir los conflictos de la vida cotidiana. El Estado era muy poco lo que intervenía en los asuntos entre particulares, escasamente lo hacía en las causas criminales. El Derecho podia dar una respuesta efectiva a la fluctuante y dinámica realidad social, que resultaba de relaciones entre particulares. Luego, con la consolidación de los Estados europeos, la figura del rey fue ganando importancia. Tanto social como políticamente, el rey empezó a acumular mayor poder, esto se vio reflejado en muchos y diversos aspectos de la vida social, especialmente en la administración de justicia. El rey hacía no solamente de árbitro en medio de las contiendas entre particulares, sino que cooptaba todo el proceso judicial, al convertirse en titular de la acción judicial, por ende, en parte principal. Hasta el momento, el principal objetivo del proceso había sido el resarcimiento o la composición del daño. A partir de que se introdujo la acción penal, la figura del rey adquirió mayor importancia dentro del proceso, al cual se le otorgó la potestad de defender el interés general y de imponer castigos, quedando la indemnización y satisfacción de la víctima en un segundo plano. La ofensa a la ley se convertía inmediatamente en una ofensa al rey, en consecuencia, este podia exigir una compensación por ello. Los reyes pronto vieron sus arcas llenas, en razón de las compensaciones que obtenían de los procesos judiciales. Surgió, entonces, la figura del procurador, un funcionario que representaba los intereses del rey en los procesos judiciales. Consecuencia de esto fue que poco a poco las partes, incluyendo el rey, dejaron de hacer presencia por ellas mismas en el proceso (iuditiostare), quedando reducido a una forma jurídica vacía.

El rey obtuvo la potestad de decir qué era legal y qué no. La ley se convirtió, entonces, en expresión de la voluntad del soberano. El Derecho devino en un proceso de abstracción ad infinitum, hasta poner su fundamento en la voluntad del rey. Ontológicamente hablando, el fundamento de la ley empezó a ponerse en cabeza del sujeto.

Hasta entonces, la intervención de los reyes en la creación y aplicación del Derecho había sido mínima, pues el Derecho, como tal, era el Derecho natural y aplicaba como Derecho de gentes o Derecho de guerra. Fue a partir del control del poder judicial y, posteriormente, de la creación del Derecho a través de edictos y leyes, que los reyes aseguraron su poder y control sobre todas las manifestaciones de la vida social. El soberano no solo encarnaba el poder político sino que encarnaba también el Derecho.

La unión sustancial entre ley y soberano se expresaba en la figura del cuerpo del rey, donde el cuerpo constituía no solo el ente visible del poder, también representaba el fundamento material del poder político. Por eso, cuando los revolucionarios franceses ejecutaron al monarca, no liquidaron únicamente el Antiguo Régimen sino que simbólicamente establecieron una nueva forma de legitimación del poder y la ley, ya no en el soberano, ni siquiera en un individuo en específico, 
sino en un sujeto sin cuerpo. El poder dejaba atrás su fundamento sustancial y empezaba a depender del acuerdo de voluntades de los individuos que se unían para formar una comunidad política. Esto es lo que hace tan característica la democracia moderna, donde el sujeto político carece de cuerpo y la ley se basa en algo menos sustancial, como el contrato social. Pasamos ahora a explicar otro estado del Derecho.

\section{DERECHO LÍQUIDO}

En el proceso de transformación de la materia, el estado que sigue al sólido es el estado líquido. Bajo condiciones especiales es posible saltar del estado sólido al gaseoso sin pasar necesariamente por el líquido, sin embargo, prueba que la presión interna de los materiales lleva a un aceleramiento de las partículas, liberando unas fuerzas impresionantes, por no decir, violentas. El estado líquido hace de estado intermedio, que sigue al derretimiento de los sólidos y antecede a la gasificación de las partículas. La misma figura de los estados de la materia se puede utilizar para dar una idea de la evolución del Derecho. Nos permitiremos utilizar el concepto de Derecho líquido para ilustrar las conclusiones del sociólogo Zigmunt Bauman, quien introdujo el término y ha desarrollado ampliamente el concepto de modernidad liquida, ${ }^{26}$ pero principalmente para sostener la tesis de que el poder creado inicialmente para la preservación del Derecho, de manera contraria, termina sometiéndolo, asfixiándolo y dejándolo inoperante frente a la compleja situación social y económica. Pero ello implica partir del problema del conocimiento, y de cómo este y el Derecho aparecen estrechamente relacionados en la nueva configuración del poder en Europa.

La Modernidad se caracterizó por el rompimiento con la época inmediatamente anterior. A pesar de que los pensadores contractualistas admitieron la preexistencia del Derecho frente al poder político, a falta de garantías del Derecho (en estado natural y absoluto) y la imposibilidad de preservarse a sí mismo, el Derecho tuvo que conformarse al contrato social y asegurar de este modo su supervivencia en la vida civil. ${ }^{27} \mathrm{~A}$ medida que el Derecho se iba incorporando a la vida cívica se iba sustrayendo también del estado de naturaleza. Por eso, a partir de la Modernidad, el Derecho empieza a definirse en contraposición a la naturaleza.

A pesar de que la Edad Media sea vista como un periodo oscuro en la historia de Occidente, en buena parte por la pérdida irreparable de la cultura clásica, no es ese bache o vacío entre dos eras gloriosas de la historia de la humanidad como han señalado, principalmente en la Modernidad. Entre la Edad Media y la Edad Antigua no se dio esa ruptura tan drástica. En la Edad Antigua, la concepción de Derecho estaba inmersa en la naturaleza misma, el orden del cosmos era resultado de una ordenación universal, por tanto, todas las cosas se entendian en función de un orden superior. Por ejemplo, en Tomás de Aquino, uno de los pensadores más

26 Cfr. Zigmunt Bauman, Modernidad liquida, op. cit., pp. 7-20.

27 Cfr. David Boucher y Paul Kelly, The Social Contract from Hobbes to Rawls, New York, Routledge, 1994. 
influyentes en el Medioevo, se encuentran trazos claros de este pensamiento inmanentista de la Antigüedad, al definir la ley, más o menos, como la ordenación de la razón dirigida al bien común y promulgada por quien cuida a la comunidad. ${ }^{28}$ Esta definición de la ley insiste en su carácter racional. La sola idea de ordenación en Tomás de Aquino hace referencia a un orden en el cosmos que no resulta ajeno a la razón, por el contrario, es puesto por la sabiduría divina y puede ser captado por el hombre gracias a la luz natural de la razón. El hombre es parte de ese cosmos; su papel, más que activo, es pasivo, y, paradójicamente, el conocimiento se activa desde la pasividad de la contemplación. ${ }^{29}$

Con el advenimiento de la Modernidad entró en crisis este concepto de cosmos. La situación política de Europa fue la causa de que se creara una distancia cada vez mayor respecto a la concepción de un orden cósmico. La transición de pequeños reinos a Estados soberanos y absolutistas trajo consigo un ambiente de inestabilidad politica. Esto, aunado a las terribles pandemias que diezmaron a la población en Europa, sembró en el hombre la sensación de vacío y desapego. Los descubrimientos científicos y geográficos sirvieron para anunciar una nueva era de la humanidad e introdujeron un nuevo sentido de la historia. El conocido giro copernicano significó un giro hacia el antropocentrismo. El interés epistemológico tomaría un nuevo curso: el hombre. Por su parte, el conocimiento de la naturaleza no volvería a asimilarse a una actitud pasiva sino a un acto de poder por definición. Sería el hombre el que impusiera un orden a la naturaleza a partir de las leyes científicas, ya no las circunstancias o el destino se impondrian al hombre de manera inexorable, determinando su existencia individual y social.

Bajo la premisa de que el hombre es cocreador del mundo donde habita, tomará cuidado de muchos aspectos de la vida social. Ya no solo era importante que el hombre encontrara su lugar en el mundo, ahora debia construir el mundo y hacerse cargo del mismo.

El capitalismo se vio beneficiado en sus inicios con la desaparición de los gremios y las corporaciones (propios de la Edad Media), esto tuvo como implicación que el hombre empezara a valorarse a través de su fuerza de trabajo. Al poderse objetivar el hombre, también las cosas (producto de su trabajo) serían susceptibles de convertirse en objetos. Los productos consisten en la suma de esfuerzos individuales. Atrás quedaba el trabajo solitario del artesano en su lugar de taller, el trabajo sería asunto de cooperación y colaboración, y el valor, o dígase el plusvalor de las cosas, estaría en el esfuerzo individual del trabajador sumado al producto mismo. La organización del trabajo especializado se vio reflejada en la división social de clases, entendida como un sistema de satisfacción de necesidades particulares. ${ }^{30} \mathrm{En}$ lo político, esta especie de socialización del trabajo fue fundamental para la concepción

28 Cfr. Tomás Aguino, Suma de Teología, Madrid, Biblioteca de Autores Cristianos, 1989, I-II, Q. 9 art. 4.

29 La contemplación es una operación racional unida, más bien, a la práctica espiritual y, en el caso del cristianismo, busca la unión de la criatura con el cosmos creado.

30 Cfr. Dudley Knowles, Routledge Philosophy Guidebook to Hegel and the Philosophy of Right, New York, Routledge, 2002. 
del contrato social y para la transición de un sistema político fundamentado en la suma de voluntades de todos los individuos.

La principal crítica que hacen autores como Bauman ${ }^{31}$ y Honneth ${ }^{32}$ - por mencionar algunos - es que la Modernidad, a pesar de la espléndida división del trabajo y la diferenciación en el espectro social, no pudo conjurar el desarrollo exacerbado de la individualidad y, por tanto, la fragmentación del cuerpo social de la que somos testigos. Honneth, por ejemplo, caracteriza este fenómeno como una patología de la libertad. ${ }^{33}$ Bauman, por su parte, lo interpreta como una fuerza centrifuga que aleja a todos los individuos del centro y debilita valores tan importantes en nuestra sociedad como la cooperación y la solidaridad. ${ }^{34}$ Bauman, al referirse a la Modernidad liquida, se refiere precisamente al hecho de que la Modernidad hace agua, y se aparta de sus ideales, no tanto por la influencia de factores externos, sino internos, que aunque estuvieran ocultos al comienzo, siguieron evolucionando hasta tomar la importancia que hoy tienen. ${ }^{35}$

Son tiempos de desencanto. Ya no hay espacio para la admiración y el asombro. El mundo y el hombre no ofrecen mayor interés para el conocimiento. Otrora, el hombre se maravillaba por los descubrimientos del mundo y lo consideraba como objeto de conocimiento. La percepción de fragmentación, incoherencia y contradicción en el mundo es reforzada por la sensación de aislamiento y superficialidad del individuo. El sujeto es tan sustituible como cualquier pieza averiada de una máquina. A nivel laboral hay más flexibilidad en la contratación, lo que hace que los vínculos sean cada vez menos estables y seguros. Como dijera Bauman: "Los empleos seguros en empresas seguras resultan solamente nostálgicas historias de viejos". ${ }^{36}$

El papel del hombre en el mundo ya no es el de productor de objetos, sino consumidor de estos; el valor de un objeto dura tanto como salga la versión mejorada del mismo, incluso antes de usarse. La lógica imperante es la del mercado. Fuerza de trabajo, relaciones sociales, objetos, el mundo todo, "es una superposición de productos para consumo inmediato". ${ }^{37}$ "A diferencia de la producción, el consumo es una actividad solitaria, incluso en los momentos en los que se consume en compañía de otros". ${ }^{38}$

La Modernidad líquida es la era de la desregulación, de la flexibilización, de la liberalización de todos los mercados. ${ }^{39}$ Detengámonos en la desregulación. El Derecho resulta, las más de las veces, inoperante frente a las situaciones sociales

31 Cfr. Zigmunt Bauman, Modernidad líquida, op. cit.

32 Cfr. Axel Honneth, The pathologies of individual freedom Hegel's social theory, Princeton, Princeton University Press, 2010.

33 Idem

34 Cfr. Zigmunt Bauman, Modernidad líquida, op. cit.

35 Idem.

36 Ibid., p. 171.

37 Ibid., p. 174.

38 Ibid., p. 175.

39 Ibid., pp. 159-160. 
que se ofrecen. El primero de los aspectos que entra en crisis es el asociado a la territorialidad del Derecho. Debido a que muchas de las actividades sociales se desarrollan por fuera del rango del Derecho quedan amplias zonas por fuera del mismo; su insustancialidad obedece a que se ha centrado de manera prevalente en la legalidad, dejando de lado fuentes que son igual de importantes y que pueden responder de manera satisfactoria a la diversidad de situaciones desreguladas.

La legalidad es un concepto nacido en Europa en el siglo XVIII, durante el periodo de transición al modelo republicano. Se basa en el imperio de la ley. Se concibió dentro de un clima de fuerte rechazo a la arbitrariedad y abuso del Derecho, principalmente en las monarquías absolutas. Todos y cada uno, incluyendo el monarca, debían someterse a la ley; ningún individuo en particular tendría privilegios; todos estarian en el mismo estatus frente a la ley. La legalidad tiene como principio fundamental el cumplimiento de la ley. Las principales características de la ley son la abstracción y la generalidad. La ley no regula una situación en particular sino que, desde su misma concepción, pretende prever todas las situaciones posibles, para ello ofrece una solución aplicable a todos los casos. Las leyes se recogen en códigos, los cuales son una expresión positiva del Derecho.

El positivismo legalista fue una de las modalidades históricas del positivismo jurídico que obtuvo su nombre precisamente de la tendencia de positivizar el Derecho a través de leyes, y consignar estas en vastos códigos. Para el positivismo, el principal cometido del Derecho, más que la justicia, es la validez. En ese sentido, para el científico del Derecho este debe depurarse de cualquier elemento empírico que impida elevarlo a reglas generales y abstractas, refiriéndose concretamente a las situaciones particulares. Para el positivista el Derecho es una ciencia al igual que las ciencias naturales; a pesar de que regula los comportamientos humanos, no deja de lado la neutralidad y la objetividad. Para el positivista, el único medio de que dispone para llegar al conocimiento es la certeza, por esa razón, el operador judicial debe alejarse de la contingencia que arroja continuamente la azarosa vida social y acogerse, más bien, a la literalidad de la ley y la seguridad y certeza que esta puede brindarle. El juez es solo un intérprete de la ley, y las pocas veces que la ley no ofrece una fórmula exacta, debe interpretar la voluntad del legislador, bajo el supuesto de que el creador de la ley es quien conoce mejor el Derecho.

La discusión entre justicia y Derecho ha ido más lejos, situándose en la diferencia entre forma y contenido de la ley. La forma hace referencia al procedimiento por medio del cual el Derecho se consagra en forma de ley, por tanto, depende de condiciones, como la autoridad de la cual emana la ley y de que se surtan ciertos trámites para que la ley obtenga fuerza de Derecho. El contenido hace referencia a las reglas, prescripciones y prohibiciones contenidas en la ley. Estas, por definición, son generales y abstractas; sin embargo, se observa que la ley, aun cumpliendo las formas para obtener fuerza de Derecho, no siempre en sus contenidos es general y abstracta, sino que puede regular casos particulares. ${ }^{40}$ Fue con el

40 Cfr. Alejandro Nieto García, Crítica de la razón jurídica, Madrid, Trotta, 2007.

DÍKAION - ISSN 0120-8942 - EISSN 2027-5366 
advenimiento de los nacionalismos que esta situación se hizo más patente. Los grupos que llegaron al poder optaron por expedir decretos con fuerza de ley en condiciones específicas -investidos, muchas veces, de facultades conferidas por la misma ley-, y llevar a cabo sus politicas. De esta manera se apropiaron, bajo el aparente manto de la legalidad, de la potestad de crear las leyes y, en buena medida, del Derecho. Estas facultades, que inicialmente fueron concebidas para situaciones excepcionales, se convirtieron luego en condiciones permanentes. De esto tenemos abundantes ejemplos en un corto periodo de tiempo en nuestro país, durante la vigencia del Frente Nacional y tiempo después. ${ }^{41}$ Vemos, entonces, que un Derecho entregado en manos del poder, se vuelve fútil, superfluo, se anula a sí mismo, trayendo como consecuencia una progresiva desregulación por parte de la ley y al gobierno por decreto.

\section{DERECHO GASEOSO}

La situación de desregulación del Derecho es aprovechada por la economía. Después de las Grandes Guerras, los países más devastados por el conflicto se endeudaron con la banca privada mediante empréstitos para iniciar su fase de reconstrucción y recuperación. Para fomentar la inversión extranjera tuvieron que dejar circular el capital con mayor facilidad. Esta coyuntura fue propicia para que la economia, de cierta forma, se sacudiera de muchos controles que la regulaban. El capital que se movia de un país a otro, para satisfacer la demanda apremiante, permitió que la economía saliera del control directo del Estado y quedara bajo sus propias leyes. Lo que han convenido en llamar desterritorialización del capital. ${ }^{42}$

La propiedad de los gases es la extrema fluidez. Para conservar dicha característica las partículas deben mantenerse en movimiento, de lo contrario, se estabilizan volviendo al estado sólido. Extrapolado al Derecho diríamos que un Derecho es sólido y goza de estabilidad, gracias a que pone su fundamento en algo tan concreto como la tierra (nomos) o el monarca. Como se dijo al inicio de este artículo, más allá de la añoranza de un tiempo pasado en que el Derecho era estable, rígido e inmutable, los nuevos tiempos exigen ponernos a su altura. Después del largo proceso de abstracción del sujeto no sigue la imposición automática de una estructura, pensada en ella misma, es preciso dar con una nueva sustancia.

En el Antiguo Régimen la unión sustancial entre ley y soberano se expresaba en la figura del cuerpo del rey, que constituía no solo el ente visible del poder sino también representaba el fundamento material del poder político. Con la liquidación del Antiguo Régimen ${ }^{43}$ el poder político dejó atrás su fundamento sustancial y empezó a depender del acuerdo de voluntades de los individuos que se unían con la intención de formar una comunidad política. El Nuevo Régimen establece

41 Cfr. Manuel IturRalde, "Guerra y derecho en Colombia: el decisionismo político y los estados de excepción como respuesta a la crisis de la democracia”, en Revista de Estudios Sociales (5) (2003), pp. 29-46, en http://res.uniandes.edu.co/view.php/472/index.php?id=472, fecha de consulta: 8 de abril de 2016.

42 Cfr. Gilles Deleuze y Félix GuATtaRi, ¿Qué es la filosofia? Barcelona, Anagrama, 1997, pp. 99-100.

43 Se refiere al modelo político basado en el Absolutismo que fue desmontado en la Revolución francesa. 
una nueva forma de legitimación del poder y la ley, de manera simbólica en un sujeto sin cuerpo. La ley se empieza a basar en algo menos sustancial, tan abstracto como el contrato social. Precisamente, la democracia se caracteriza porque el sujeto político carece de cuerpo.

El camino recorrido desde la ley/nomos, en cuanto ley vinculada al factor de la tierra en la Grecia arcaica, a la ley expresión de un sujeto sin cuerpo, correspondiente a la democracia moderna, muestra un proceso de desmaterialización del Derecho. El Derecho pasa a un estado gaseoso; se desmaterializa en tanto deviene abstracto, es decir, de algo tan sólido y estable como el territorio, el Derecho pone su fundamento en un concepto tan abstracto y volátil como el individuo.

La Modernidad deviene en fragmentación del cuerpo social. Esto no es un hecho novedoso, sino que obedece a la radicalización de factores inherentes pero que solo hasta el momento se hacen manifiestos. La Modernidad es interrupción infinita y conlleva la atomización del poder en una infinidad de cuerpos. ${ }^{44}$ Esta atomización es resultado de un desarrollo de la particularidad que requiere la separación radical de los otros. ${ }^{45}$ La sociedad se mueve de la unidad simple e inmediata a una individuación y separación progresivas, en la que los individuos se separan unos de otros y de la comunidad, pero más tarde se ve cómo el individuo se reintegra a la comunidad y la separación es superada. Ambos momentos son necesarios en el proceso de desarrollo de los individuos en comunidad, ninguna de las dos subsiste por sí misma, tanto para negar la autonomía de los sujetos como para provocar la desintegración interior en las personas y de sus conexiones sociales. ${ }^{46}$ Los individuos, en la consecución de sus metas, parecen alejarse de las metas en común, por eso es que resulta tan dificil y conflictiva la convivencia social, y el mundo parece habitado por de mónadas, cada uno con la misma pretensión de reivindicar su derecho de manera absoluta frente a los demás.

El Estado-nación westfaliano, basado en la soberanía absoluta, es devorado desde sus entrañas y ahogado por su propia bilis. No hay que negar que desde siempre estuvo alojada en su interior la fragmentación; sin embargo, ahora viene de miles y millones que se le oponen.

El Derecho pasa a un nuevo estado, después de estar subyugado al poder, ahora es el poder que se sujeta al Derecho, recobrando este último el lugar que le corresponde en la sociedad. Antes, el Estado-nación tradicional servía de contención a las fuerzas económicas contingentes; ahora, con la aparición de las multinacionales y los capitales de riesgo el control estatal es insuficiente. Las fuerzas económicas, lejos de regirse a sí mismas campean libremente sometiendo todo a la lógica de

44 Cfr. Amalia Boyer, "Materialismo ontológico y política en Spinoza, Deleuze y Guattari", en Eidos (1) (2003), pp. 94-106, en: http://rcientificas.uninorte.edu.co/index.php/eidos/article/ view/1524/991, fecha de consulta: 8 de abril de 2016. of Liberalism”, en Science \& Society 71 (1) (2007), pp. 84-102. 
mercado, tan propia de un capitalismo salvaje. No es cierto que las fuerzas económicas quedan bajo una mano invisible que las dirige, como lo supusieron los primeros teóricos (Adam Smith, David Ricardo y Jean-Baptiste Say) y que el mercado se autonomice. La economía no puede agenciarse por sí misma, precisa de una sustancia universal que controle la fuerte polarización que se da en su interior.

Han sido varios los autores que han desarrollado el concepto de sustancialidades éticas ${ }^{47}$ para referirse a formas de vida ética o comunidades, donde el problema central es la armonización de la existencia individual y la existencia social del hombre. La libertad de los individuos no se desvirtúa por el hecho de vivir en referencia a una sustancialidad ética, al contrario, el individuo se reconoce como tal si pertenece a una comunidad sustancial, porque solo alli puede interactuar con otros sujetos libres como él y ser reconocido por estos. En un mundo globalizado, las sustancialidades éticas se encuentran seriamente afectadas y las libertades así como distintas formas de organización social y política se ven comprometidas.

La libertad precisa de instituciones y mediaciones para realizarse en el mundo. El sujeto alcanza la tan anhelada libertad sustancial ${ }^{48}$ en la medida que renuncia voluntariamente a la libertad abstracta ${ }^{49}$ que le viene por naturaleza. Esta libertad en estado puro, concebida en la Modernidad, tiene su mayor realización en la propiedad privada y en la moralidad, sin embargo, no logra conciliarse del todo con el mundo objetivo y resulta todavía contingente. No es a través de la libre empresa y el libre cambio (postulados del capitalismo) como se realiza la libertad individual, antes bien, la versión radicalizada de estos puede tornarse causa de su autodestrucción. La manera de conjurar los movimientos compulsivos de la economía es mediante la conformación de sustancialidades éticas.

Se habla hoy de un Estado constitucional, ${ }^{50}$ como tendencia a nivel global. El nuevo paradigma posibilita que en el Estado social de derecho haya realización de la justicia material y que los individuos estén más cerca del aparato estatal y del sistema internacional, a su vez, los derechos tienen mayor garantía de ser protegidos. El Estado constitucional es la adaptación del Estado de derecho, donde los derechos fundamentales constituyen el fundamento de la dimensión sustancial y no solo formal de la democracia. ${ }^{51}$

La conciencia creciente de los derechos humanos ha prohijado la creación de un sistema internacional de protección de los mismos. Se habla incluso de una cultura de los derechos humanos para referirse a un sistema de pensamiento inspirado en el concepto de dignidad humana. Actualmente, cuando los centros tradicionales del

47 Cfr. Georg Wilhelm Friedrich Hegel, Fundamentos de la Filosofia del Derecho, Madrid, LibertariasProdhuri S.A, 1993. Charles TAYLOR, La ética de la autenticidad, Barcelona, Paidos, 1994.

48 Cfr. Herbert Marcuse, Razón y Revolución, Madrid, Alianza, 1984, pp. 200-201.

49 Ibid., pp. 200-201.

50 Cfr. Rodolfo VIGo, Constitucionalización y judicialización del derecho del Estado de derecho legal al Estado de derecho constitucional, Bogotá, Grupo Editorial Ibáñez, 2012.

51 Cfr. Luigi Ferrajoli, Fundamento de los derechos Fundamentales, 4 ed., Madrid, Trotta, 2009, pp. 35-40. 
poder político (Estados nacionales) se diluyen y tienden a expandirse las zonas de desregulación del Derecho, las personas - parece- quedan desprotegidas y a merced de los embates de un capitalismo esquizoide, del terrorismo, del crimen global y del deterioro del medio ambiente. Estos problemas afectan a toda la humanidad y toman fuerza de la incapacidad del ordenamiento jurídico interno para conjurar estos efectos, especialmente en los países subdesarrollados. Empresas que infringen la ley al amparo del Derecho, la amenaza de un terrorismo global, redes criminales dedicadas a la trata de personas o al tráfico ilegal que traspasa las fronteras, el daño irreparable al medio ambiente por el que nadie se hace responsable, ponen el Derecho al limite.

Está visto que la ley no es suficiente para conjurar estos males, por esa razón una nueva forma de regulación es a través de los derechos humanos. Casi todos los países han adoptado los derechos humanos dentro de su ordenamiento interno en forma de principios. Este cambio de paradigma se refleja inmediatamente en la aplicación del Derecho. Vemos, entonces, que para decidir sobre un asunto los jueces se apegan menos a la ley, y optan, más bien, por una interpretación del Derecho con base en principios para poder dar respuesta a los nuevos problemas que se presentan. ${ }^{52}$

Paralelo al Derecho constitucional ha tomado fuerza el Derecho convencional, que vincula el Estado a un sistema internacional, transfiriéndole una cantidad de cargas y responsabilidades que antes no estaba obligado a asumir dentro de su ordenamiento interno, con amparo en el principio de soberanía. No entraremos a ver la redefinición de la soberanía en el Estado de derecho constitucional, por razones de espacio.

Pues bien, aunque el Derecho convencional imponga de manera indirecta nuevas cargas al Estado permite también reforzar los vínculos de cooperación y colaboración entre los Estados para contrarrestar amenazas que ponen en riesgo a toda la humanidad. El sistema internacional permite responsabilizar nuevos actores, fuera de los Estados, que antes simplemente eran invisibles al Derecho, tales como empresas transnacionales, organizaciones terroristas o del crimen organizado, entre otros.

\section{El DERECHO Y LAS CIENCIAS DE LA NATURALEZA}

"La experiencia jurídica es una experiencia radicalmente humana, pero específicamente es una experiencia de vida humana en sociedad". ${ }^{53}$ Sin embargo, esta visión de lo jurídico es incompleta si no relacionamos el Derecho con la supervivencia de 
la vida en el planeta, ${ }^{54}$ puesto que no solo su alcance, también sus disposiciones se legitiman por el vínculo y la responsabilidad con las generaciones futuras. ${ }^{55}$

Esta relación entre Derecho y biologia dota al primero de cierta apertura, de un indeterminismo que pocas veces había probado.

La biología al referirse a los organismos como sistemas abiertos, o dependientes parcialmente de las condiciones de entorno no puede prometer ningún tipo de predicción determinista, a lo más que podría aspirar es a la predicción estadística, renunciando a la certeza y las posibilidades mismas del control. ${ }^{56}$

El Derecho, al igual que la vida, tiende al cambio. Cabe preguntarse si ese cambio se convierte en ley, es decir, si está en permanente movimiento. "La evolución, aunque dirigida y orientada hacia una mayor complejidad, es abierta e impredecible", ${ }^{57}$ en ese sentido, "la ley de evolución y cambio es una ley que evoluciona". ${ }^{8}$ Si la ley de cambio es una ley que evoluciona hay que aceptar que existe una ley absoluta, entonces, es probable que haya cierto determinismo por encima de la evolución de la vida, que sería la ley de evolución del universo.

Los avances de los físicos Rudolf Clasius (1822-1888) y Ludwing Boltzmann (18441906) en la termodinámica permitieron introducir el concepto de entropía, que se define como la cantidad de energía térmica que se pierde en un sistema aislado, y pone el caso hipotético del fin del universo. El universo es un sistema aislado, y su entropía con el tiempo crece de modo constante hasta un valor máximo que coincide con la uniformidad térmica. La entropía del Universo marca un sentido a la evolución del mundo físico, conocido como principio de evolución, en el que no hay energía libre para crear y mantener la vida y otros procesos. La evolución, como proceso lejano del equilibrio, se caracteriza por un espacio fase en incremento, y por una tendencia a la expansión que va retrasada con respecto al máximo de entropía

54 "Si aceptamos que los niños, púberes y los adultos jóvenes hacen parte de las [generaciones futuras] y pueden representarlas hoy, en el presente debemos permitir que ellos participen en las decisiones que afectan el ambiente, la cultura y la educación, puesto que las decisiones que hoy tomamos afectan de manera directa su futuro y el futuro mismo de la permanencia de la vida como la conocemos". Alexander LóPEz-Quiroz, "Generaciones futuras y personalidad jurídica”, en Díkaion 23 (2) (2014), p. 272, en: http://dikaion.unisabana.edu.co/index.php/dikaion/article/ view/3655/3814, fecha de consulta: 8 de abril de 2016 .

55 “[el] arquetipo clásico de toda responsabilidad [es] la de los padres por el hijo. Arquetipo tanto en una perspectiva genésica como tipológica, pero también, en cierta medida, en una perspectiva "gnoseológica", meced a su evidencia inmediata. El concepto de responsabilidad implica el de deber, primero el de deber-ser de algo, después, el de deber-hacer de alguien en respuesta a ese deberser. Es prioritario, por tanto, el derecho intrínseco del objeto. Solo una exigencia inmanente al ser puede fundar objetivamente el deber de una causalidad transitiva en el ser (que vaya de un ser a otro). La objetividad ha de venir del objeto". Hans Jonas, El principio de responsabilidad, Barcelona, Herder, 1995, p. 215.

56 Eugenio Andrade, "Mecánica estadística, Neodarwinismo y la prefiguración de las ciencias de la complejidad", en Acta Biológica Colombiana (14) S (2009), p. 185, en http://www.revistas.unal. edu.co/index.php/actabiol/article/view/10681/20490, fecha de consulta: 8 de abril de 2016 .

57 Ibid., p. 184.

58 Idem.

AÑo 30 - Vol. 25 Núm. 1 - ChíA, Colombia - Junio 2016 
del universo. ${ }^{59}$ Sin embargo, el profesor Eugenio Andrade, basado en evidencia científica, permite concluir que la materia y la vida, en lugar de tomar distancia con el paso del tiempo, por el contrario, llegan a su máximo acercamiento. La evolución, en vez de retrasarse respecto al universo, sigue su curso a una mayor diversificación genética, por tanto, no cabe hablar de una inminente muerte del universo o algo por el estilo.

El aumento en el grado de expansión o diversificación a lo largo del tiempo, está evidenciado por ejemplo en los números promedios de genes existentes en los diferentes grupos, para procariotas alrededor de 5.000, eucariotas invertebrados alrededor de 10.000 y vertebrados alrededor de 25.000 genes. La expansión brusca en el número de genes y variantes alélicas, genera una expansión exponencial del espacio genotípico. Este fenómeno permite entender mejor la existencia de variaciones neutras. La diversidad real o el valor real de entropía está dado en mayor proporción por las variaciones neutras, por tanto, la evolución es el resultado de la tendencia al aumento de la variación neutra que facilita acceder a posibles variantes adaptativas. ${ }^{60}$

Si el Derecho evolucionó a un Derecho convencional entre los Estados, favoreciendo la formación y consolidación de un sistema multilateral, y la realidad social ha hecho de esta disciplina un terreno especialmente fecundo, no cabe hablar de un agotamiento o posible muerte del Derecho, como se pensó en un momento; todo lo contrario, el Derecho va camino a una expansión sin precedentes, pues a pesar de basarse en un único sistema formal, acepta múltiples sistemas que participan en la creación continua de la realidad jurídica; lo suyo es la unificación, pero sabe que "la unificación requiere aceptar el carácter temporal asociado a la evolución". ${ }^{61}$

\section{CONCLUSIONES}

El artículo aborda un problema bastante complejo en la historia de las ideas jurídico-políticas en Occidente, esto es, el tránsito entre los distintos paradigmas del Derecho, o, lo que es lo mismo, las distintas formas de comprender la noción de Derecho a partir de los giros, las continuidades y las rupturas sociales, económicas y politicas, en general. Cada uno de los periodos mencionados ocupa vastas y complejas reflexiones en distintos autores y campos disciplinares. El presente artículo no se propuso sintetizar los cambios históricos del Derecho in extenso ni tampoco hacer notar las grietas, yuxtaposiciones y dislocaciones en los distintos periodos, en la medida que se hacía un mapeo bastante extenso, corriendo el riesgo permanente de quedar en una mera descripción. En lugar de escuchar la profundidad de las épocas históricas del Derecho, la exposición se apartó de la lectura lineal que sugiere la historia y presentó las categorías de Derecho sólido, líquido y gaseoso como una opción metodológica para entender su devenir, y más que categorías históricas, como categorias ontológicas del Derecho. En otras palabras, este estudio acerca de la naturaleza del Derecho se propuso, realmente,

\begin{tabular}{ll}
\hline 59 & Idem. \\
60 & Idem. \\
61 & Idem.
\end{tabular}


responder a la pregunta por el ser del Derecho, a través de un estudio genético del mismo. La certeza, la seguridad y la estabilidad, otrora deificadas por los glosadores, parecen diluirse con el tiempo. A cambio, el derecho parece sumirse en la incertidumbre, la inseguridad y la inestabilidad. La tendencia del mundo contemporáneo marca una marcha del Derecho al estado de naturaleza, pero más que regresión o involución, estos cambios sugieren un nuevo estado en su evolución.

Obviamente que a un nuevo Derecho se deben nuevos intérpretes que lo apliquen; sin embargo, muy poco se haría si no se adaptan las formas de enseñanza en el proceso de formación de los juristas y de los futuros intérpretes; esto difícilmente es realizable si los maestros no admiten la necesidad de nuevos enfoques que permitan entender los fenómenos a los que se enfrenta el Derecho, partiendo de su comprensión y su dinámica en un mundo cambiante.

El Derecho gaseoso no es una mutación, es una consecuencia del mismo. Suele pensarse que el orden se separa del estado original de caos; no obstante, la física ha enseñado que también hay un caos procedente del orden. Aunque pueda parecer que el universo avance de modo inexorable al caos y a su propia muerte, el misterio de la eternidad de la vida — como dijera Einstein- continúa construyendo de manera prodigiosa lo existente. El Derecho también está sujeto a esta ley del cambio, y puede parecer que cede terreno al caos y al desorden, pero no hay que olvidar que el Derecho precisa él mismo del cambio, al encontrar en el mundo de la vida su máxima expansión. Es hora de que el Derecho se reencuentre a sí mismo en la Naturaleza y, de este modo, siga haciendo presencia en el mundo.

\section{REFERENCIAS}

Alexy, Robert, Interpretación Constitucional, vol. 2, México, Porrúa, 2005.

Andrade, Eugenio, "Mecánica estadística, Neodarwinismo y la prefiguración de las ciencias de la complejidad”, en Acta Biológica Colombiana, 14 S (2009), pp.169-186, en http://www.revistas.unal.edu.co/index.php/actabiol/article/ view/10681/20490, fecha de consulta: 8 de abril de 2016.

Aguino, Tomás, Suma de Teología, Madrid, Biblioteca de Autores Cristianos, 1989.

ARIstóteles, Física, Madrid, Gredos, 1998.

Ávila VÁsguez, Manuel Oswaldo, "En torno a la sentencia de Anaximandro. Dos interpretaciones sobre la justicia”, en Universitas Philosophica (56) (2011), pp. 61-83, en: http://revistas.javeriana.edu.co/index.php/vniphilosophica/article/view/11030/9041, fecha de consulta: 8 de abril de 2016.

BARBIERI, Javier, "Physis frente a nomos: el eterno retorno", en Díkaion 20 (1) (2011), pp. 71-82, en http://www.scielo.org.co/pdf/dika/v20n1/v20n1a04.pdf, fecha de consulta: 8 de abril de 2016 . 
Bauman, Zigmunt, Modernidad liquida, Buenos Aires, Fondo de Cultura Económica, 2002.

Boucher, David y Kelly, Paul, The Social Contract from Hobbes to Rawls, New York, Routledge, 1994.

Boyer, Amalia, "Materialismo ontológico y política en Spinoza, Deleuze y Guattari”, en Eidos (1) (2003), pp. 94-106, en http://rcientificas.uninorte.edu.co/index. php/eidos/article/view/1524/991, fecha de consulta: 8 de abril de 2016.

Deleuze, Gilles y Guattari, Félix, ¿Qué es la filosofia?, Barcelona, Anagrama, 1997.

DERRIDA, Jacques, Adiós a Emmanuel Lévinas. Palabra de acogida, Madrid, Trotta, 1998.

FERRAJOLI, Luigi, Fundamento de los derechos fundamentales, 4 ed., Madrid, Trotta, 2009.

Foucault, Michel, La verdad y las formas jurídicas, Barcelona, Gedisa, 1992.

Galatı, Elvio, "Visión compleja de los paradigmas científicos y la interpersonalidad en la ciencia”, en Cinta moebio (44) (2012), pp. 122-135, en http://www. scielo.cl/pdf/cmoebio/n44/art03.pdf, fecha de consulta: 8 de abril de 2016 .

GARCÍA JimÉnez, Leonarda, "Aproximación epistemológica al concepto de ciencia: una propuesta básica a partir de Kuhn, Popper, Lakatos y Feyerabend”, en Andamios 4 (8) (2008), pp. 185-212, en http://www.scielo.org.mx/scielo. php?script=sci_arttext\&pid=S1870-00632008000100008, fecha de consulta: 8 de abril de 2016.

Grossi, Paolo, Mitología jurídica de la modernidad, Madrid, Trotta, 2003.

Hegel, Georg Wilhelm Friedrich, Fundamentos de la Filosofia del Derecho, Madrid, Libertarias-Prodhuri, 1993.

Honneth, Axel, The pathologies of individual freedom Hegel's social theory, Princeton, Princeton University Press, 2010.

ItURRALDE, Manuel, "Guerra y derecho en Colombia: el decisionismo político y los estados de excepción como respuesta a la crisis de la democracia”, en Revista de Estudios Sociales (5) (2003), pp. 29-46, en http:/ / res.uniandes.edu.co/view. php/472/index.php?id=472, fecha de consulta: 8 de abril de 2016.

JAEGER, Werner, Alabanza de la ley. Los origenes de la filosofia del derecho y los griegos, Madrid, Instituto de Estudios Políticos, 1953.

JonAs, Hans, El principio de responsabilidad, Barcelona, Herder, 1995.

Knowles, Dudley, Routledge Philosophy Guidebook to Hegel and the Philosophy of Right, New York, Routledge, 2002.

LóPEz-Quiroz, Alexander, “Generaciones futuras y personalidad jurídica”, en Díkaion 23 (2) (2014), pp. 251-275, en http://dikaion.unisabana.edu.co/index.php/ dikaion/article/view/3655/3814, fecha de consulta: 8 de abril de 2016 .

MARCuse, Herbert, Razón y Revolución, Madrid, Alianza, 1984. 
Mondolfo, Rodolfo, El pensamiento antiguo, vol. 1, Buenos Aires, Losada, 1942.

Nieto García, Alejandro, Crítica de la razón jurídica, Madrid, Trotta, 2007.

Pamparacuatro, Javier, "En torno a la crisis del Derecho", en Revista de Derecho Político (92) (2015), pp. 165-194, en http://revistas.uned.es/index.php/derechopolitico/article/view/14424/12882, fecha de consulta: 8 de abril de 2016.

PAmpillo-BAlĩ̃o, Juan Pablo, "Una teoría global del Derecho para una nueva época histórica”, en Díkaion 19 (1) (2010), pp. 11-45, en: http://dikaion.unisabana. edu.co/index.php/dikaion/article/view/1701/2199, fecha de consulta: 8 de abril de 2016.

RoJAs AmANDI, Víctor Manuel, "Cuatro paradigmas de la epistemología jurídica”, en Juridica: Anuario del Departamento de Derecho de la Universidad Iberoamericana (36) (2006), pp. 385-420, en http://www.juridicas.unam.mx/publica/ librev/rev/jurid/cont/36/pr/pr23.pdf, fecha de consulta: 8 de abril de 2016.

RuIZ PIÑEIRo, Fernando Luis, "Sociedad subsiguiente a la Modernidad, seguridad jurídica diluida y jueces en proceso de licuefacción”, en Nómadas (26) (2010), pp. 1-12, en http://www.redalyc.org/articulo.oa?id=18118916001, fecha de consulta: 8 de abril de 2016.

SAYERS, Sean, "Individual and Society in Marx and Hegel: Beyond the Communitarian Critique of Liberalism”, en Science \& Society, 71 (1) (2007), pp. 84-102.

Solaz-Portolés, Joan Josep, "Sobre cómo el conocimiento científico intenta aproximarse a la realidad”, en Revista Brasileira de Ensino de Física 34 (3) (2012), pp. 1308-1-1308-5, en http://www.scielo.br/pdf/rbef/v34n1/v34nla08.pdf, fecha de consulta: 8 de abril de 2016.

TAYLor, Charles, La ética de la autenticidad, Barcelona, Paidos, 1994.

TEnA, Rodrigo, "Derecho líquido. Reflexiones en torno a la Ley 41/2007 de Reforma Hipotecaria”, en El Notario del siglo XXI (25) (2009), en http:/ /www.elnotario.es/ index.php/academia-matritense-del-notariado/1604-derecho-liquido-reflexiones-en-torno-a-la-ley-41-2007-de-reforma-hipotecaria-0-2764456144314684, fecha de consulta: 8 de abril de 2016.

Tena, Rodrigo, “Derecho líquido y abuso de poder”, en El Mundo, 2009, en http:// www.elmundo.es/opinion/tribuna-libre/2009/09/19536117.html, fecha de consulta: 8 de abril de 2016.

VIGo, Rodolfo, Constitucionalización y judicialización del derecho: del Estado de derecho legal al Estado de derecho constitucional, Bogotá, Grupo Editorial Ibáñez, 2012. 